\title{
O sistema de produção de teledramaturgia na RBS TV
}

\section{RESUMO}

O artigo apresenta e analisa o processo de produção audiovisual da RBS TV Porto Alegre, emissora-mãe do Grupo RBS, com geração para todo o Rio Grande do Sul. A partir da Economia Política da Comunicação, discutese a evolução histórica deste Núcleo de Programas Especiais e contextualiza-o no mercado televisivo, para isso efetuando levantamento dos vídeos produzidos, revisão bibliográfica, captura de dados junto à emissora e outros agentes e realização de entrevistas com os principais envolvidos.

\section{PALAVRAS-CHAVE}

economia política da comunicação

mídias audiovisuais

comunicação

\section{ABSTRACT}

The article presents and analyzes the audiovisual production process of RBS TV Porto Alegre, issuing parent of RBS Group, genrating for the entire Rio Grande do Sul. From the Political Economy of Communication, discusses the historical evolution of the Center for Special Programs and contextualizes it in the TV market, making it to a survey of videos produced, literature review, capture data from the station and other staff and carrying out interviews with people involved.

\section{KEY WORDS}

political economy of communication

audiovisual media

communication

\section{Valério Cruz Brittos}

Professor do Programa de Pós-Graduação em Ciências da Comunicação da UNISINOS/RS/BR

val.bri@terra.com.br

\section{Jéssica do Vale Luz}

Graduada em Comunicação Social/Jornalismo pela UNISINOS/RS/BR jessluz@gmail.com
0 projeto de produzir ficção para televisão no Rio Grande do Sul existe há muito tempo, mas só em 1999 a ideia ganhou lugar na grade da emissora a partir do surgimento de um espaço vago na programação dos sábados à tarde. No início da década de 80 , houve uma primeira e frustrada tentativa de produzir um programa especial dentro da RBS TV, envolvendo inclusive um teste de elenco com mais de 700 pessoas.

Em 1999, a proposta era colocar no ar, durante um mês, quatro curtas-metragens produzidos no Estado, dos mais conhecidos e premiados diretores. A série foi intitulada Curtas Gaúchos e teve uma receptividade extremamente positiva, tanto em termos de audiência, quanto de retorno financeiro aos patrocinadores. O que era para ser uma série de poucos episódios transformou-se na exibição de 76 curtas gaúchos.

O sucesso da estreia de ficção da RBS TV consolidou espaço e horário (sábados, 12h20min) reservado à exibição de produções com temática, técnicos, diretores e roteiristas locais. Mesclando documentários, reconstituições e ficção, rapidamente desenvolveu-se o Núcleo de Programas Especiais da emissora. Com uma estrutura física simples, estabeleceu-se um sistema de terceirização de produção, que gerou trabalho para centenas de profissionais de produção audiovisual. Os diretores formaram sua equipe, trazendo para o Núcleo produtores assistentes, roteiristas, fotógrafos e elenco. Muitos dos profissionais envolvidos trouxeram sua experiência da publicidade, cinema e vídeo. Com uma coordenação de produção e direção geral interna, a diversidade de estilos tornou mais atrativos os conteúdos exibidos.

Desde o início, tem sido incontestável a inovação em termos de linguagem e de relação com o mercado de trabalho. O telespectador leigo tende a comparar a qualidade artística e técnica da dramaturgia regional com a da Rede Globo, o que exige da direção do Núcleo uma enorme cautela na aprovação dos programas exibidos, em meio a orçamentos apertados. De qualquer forma, a produção da emissora tem conquistado importantes pontos de audiência e o respaldo do mercado publicitário, consolidando as séries locais como bons produtos de veiculação comercial.

Esse retorno cooperou na conquista de um segundo espaço (sazonal) na grade (domingos, 00h00, após o programa Teledomingo). Em 2005, estrelou a série Cinco Vezes Erico, no ano seguinte lançou o projeto Quintana Anjo e Poeta e a ousada adaptação da obra de Josué Guimarães, A Ferro e Fogo. Em 2007, foi exibida a série Escritores e o programa O Legado Lutzenberger.

Neste texto, parte-se da problemática central de como funciona o sistema de produção do Núcleo de Programas Especiais da RBS TV para contextualizar o sistema de produção no mercado de televisão gaúcha com base 
na Economia Política da Comunicação (EPC). Há um consenso de opiniões sobre a importância da produção local no estímulo ao consumo televisivo. O espectador, ao ter acesso a uma programação regional, desenvolve um sentimento de proximidade com o conteúdo exibido, que se torna fator essencial de identificação afetiva e geográfica.

\section{Juntamente com a urbanização, a educação e outras forças sociais, a mídia gera recursos que estimulam a progressiva modernização econômico- cultural.}

O universo de pesquisa limita-se a um levantamento no período entre janeiro de 1999 e julho de 2007. Para a reconstrução da riqueza do objeto analisado, e visando entender o funcionamento do Núcleo de Programas Especiais da RBS TV, utilizaram-se essencialmente as seguintes técnicas, para a captura de dados: 1) pesquisa de dados quantitativos; 2) bibliografia acerca do eixo teórico proposto; 3) entrevistas com o objetivo de registrar a história do meio televisivo local, com foco no Núcleo, e obter informações práticas até então não publicadas.

\section{Economia política e indústria}

Restritamente, o estudo das relações sociais, em especial das relações de poder, que constituem a produção, a distribuição e o consumo de recursos, incluindo os da comunicação, define economia política, conforme Mosco (1999). Nesse sentido, compreende-se Economia Política da Comunicação como o eixo teórico-metodológico que estuda a distribuição da produção, distribuição e consumo de recursos comunicacionais, no âmbito de sociedades de classes, demarcadas, portanto, por relações assimétricas de poder. Trata-se de um construto desenvolvido a partir da contribuição fundamental de Karl Marx, nos marcos do materialismo histórico dialético, trabalhando com variadas técnicas de pesquisa e dialogando com outras angulações.

A EPC envolve as definições de economia, teoria política, direito, sociologia, psicologia e demais aéreas da comunicação. Conforme Lopes da Silva, a Economia Política da Comunicação:

Procura explicar duma maneira satisfatória e global as relações entre a Comunicação e as formas de distribuição da riqueza e do poder na sociedade; como se estruturam e reproduzem as relações de legitimação sócio-política, ou seja, as formas de domínio e de desigualdade e qual é aí o papel da Comunicação; e quais são as conseqüências sócioculturais do intercâmbio de Comunicação no sistema econômico e cultural mundial (Silva, 2006, p. 7).

Juntamente com a urbanização, a educação e outras forças sociais, a mídia gera recursos que estimulam a progressiva modernização econômico-cultural. O crescimento da mídia tem sido apontado como um indicador de desenvolvimento. Não obstante, deve-se matizar tal assertiva, já que não se trata de uma simples matematização de equipamentos, veículos e produtos midiáticos. Deve-se refletir sobre os padrões tecno-estéticos envolvidos, o grau de diversidade do acesso e da participação, e o nível de intronização sistêmica do conhecimento envolvido, que não deve ser apropriado só privadamente.

Tópicos como público-alvo, definição de temáticas e formatos, publicidade nos intervalos comerciais, condições técnicas disponíveis, assim como concorrência e dados de audiência, estão inseridos nos marcos da EPC. Esses itens encaixam-se no sistema de transição pelo qual passam os meios de comunicação atuais, especificamente a televisão.

A ideia da interligação entre meios, internet e televisão, por exemplo, abre um leque de possibilidades ao espectador, que pode optar pelo produto de sua preferência, frente a uma conjunção de fatores, onde o poder aquisitivo é fundamental. Isto caracteriza a Fase da Multiplicidade da Oferta da Comunicação (Brittos, 2006, p. 15). Além da chegada de novos canais, são indícios deste novo período o barateamento ao acesso das novas tecnologias, a busca de satisfação imediata por parte do consumidor e o acirramento da disputa intra e intermídias.

Nessa conjuntura, o surgimento de uma infinidade de novos canais intensifica no Brasil a disputa pela audiência, mas a TV aberta continua a mais forte e influente indústria cultural do mundo. O barateamento dos televisores multiplicou o número de espectadores. No entanto, foi-se o tempo que famílias inteiras sentavam em frente ao televisor para assistir à programação de uma mesma emissora. Hoje, é acirrada a luta entre os meios de comunicação, que disputam a atenção dos espectadores minuto a minuto. A TV aberta já não dá conta das expectativas de consumo, podendo seu conteúdo ser flexibilizado e assistido em várias mídias.

Considerando esses elementos a partir da EPC, tomam-se as empresas que constituem o Grupo Rede Brasil Sul (RBS) por indústrias culturais. Independente de suas inúmeras definições, o termo desenvolvido por Adorno, em texto publicado originalmente em 1947, hoje recebe várias leituras. Segundo Bustamante (1999, p. 25):

o conceito de Indústria Cultural designa a transformação de uma parte da cultura, capaz de integrar 
um trabalho criativo, em uma matriz tecnológica e industrial para transformá-lo em um produto destinado a ser vendido a um público massivo.

Num conceito geral, a Indústria Cultural produz obras que são feitas em série e deixam de ser instrumentos de livre expressão, trabalho e reflexão intelectual, para se tornarem produtos comercializáveis e que são consumidos de forma perecível.

\section{Hoje também o espaço local está valorizado, demandando investimento em produção regional. 0 espectador sente-se representado ao ter acesso também às notícias de seu bairro.}

Num modelo capitalista de elevada concentração e centralização de capital, em que foi desenvolvido um amplo mercado consumidor, a atuação da indústria de diversão incentiva a produção, a circulação e o consumo de bens simbólicos, demarcando os limites da definição de Indústria Cultural (Brittos; Miguel, 2008). Este modelo coloca a TV num padrão mercantilista similar ao mercado tradicional, com a missão de comercializar produtos (audiência e cultura) e provocar a plena inserção do cidadão no sistema.

Um dos principais objetivos das organizações televisivas abertas generalistas é a maximização do número de espectadores durante o maior tempo possível, de forma que a produção em massa gere grande afluxo de capital às empresas televisuais. Por esse caminho, a regra tem sido a distribuição de um mesmo conteúdo nacional ou até internacionalmente, em termos de televisão.

No entanto, ao lado deste modelo de escala, hoje também o espaço local está valorizado, demandando investimento em produção regional. O espectador sente-se representado ao ter acesso também às notícias de seu bairro. Llobet (2000) crê na necessidade de uma redefinição dos marcos da globalização, pois é cada vez mais notável o reconhecimento das identidades locais e regionais. Nas últimas décadas do século XX, o avanço das tecnologias aproximou os acontecimentos do mundo.

Mas o próximo (considerado o ocorrido em uma área não muito distante vinculada com características antropológicas, culturais, econômicas, políticas e sociais compartilhadas pelos receptores) é sempre mais atraente para o público, porque dá à notícia um valor intimamente vinculado ao cotidiano (Llobet, 2000).
Para a Rede Globo, o localismo é uma importante característica que justifica o sistema de afiliação. Ao mesmo tempo em que cobre o mundo através da veiculação dos principais fatos internacionais, exibição de filmes e seriados estrangeiros, alcança os telespectadores da forma mais completa, noticiando através das suas afiliadas os acontecimentos de cada região.

Dentro de um processo de identificação e inserção, o local se torna um elemento significativo no estímulo do consumo de televisão, contribuindo, inclusive, com o desempenho da audiência da Rede Globo (Kurth, 2006). O sucesso da programação local da RBS TV gera a fidelização desejada por ambos os grupos, ou seja, provoca a lealdade de um cliente satisfeito com o serviço oferecido.

\section{Afiliação e Núcleo}

Afiliada da Rede Globo desde 1969, a RBS é o maior grupo de comunicação do Rio Grande do Sul e de Santa Catarina. Composta por rádios AM e FM, canais de televisão, jornais e portais na internet, em 2008 completou 51 anos. Além das características administrativas, o padrão Globo de qualidade está presente nas produções locais.

A partir do site da direção geral de comercialização da Rede Globo conclui-se rapidamente que a RBS TV é a afiliada com maior produção local. Na grade de programação observam-se 12 programas de produção própria, além de um segundo espaço utilizado sazonalmente pelo Núcleo de Programas Especiais, aos domingos, após o Teledomingo.

A RBS TV de Porto Alegre é uma afiliada da Rede Globo e está sujeita às condições da cabeça de rede para que o convênio se mantenha. A influência das afiliadas ocorre no sentido de conquistar a fidelidade do espectador, que se sente representado ao ter acesso às notícias de sua cidade pelo mesmo canal que o informa sobre fatos internacionais. Para que não haja uma disparidade no material produzido, a emissora mãe (Globo) exige que sejam seguidos fielmente os padrões de qualidade estabelecidos.

Existe um controle para que as afiliadas não ultrapassem os limites regionais. Conforme o gerente de programação da RBS TV: "Não é de interesse da Rede Globo que uma afiliada localizada no sul do país produza um programa sobre a Amazônia, a não ser que o assunto do programa seja relacionado à cultura gaúcha" (Simões, 2007).

Almeida Filho resume o funcionamento do sistema de afiliadas da Globo e especifica as condições estabelecidas:

1. a Globo fornece a programação de graça, mas exige a manutenção do padrão de qualidade da Central Globo de Produções;

2. através da Central Globo de comercialização, a Globo vende os anúncios de suas afiliadas no mercado nacional, ficando com $50 \%$ desse faturamento 
para si. À afiliada cabe com exclusividade a comercialização do seu mercado regional (Filho, 1976, p. 65).

Mesmo sendo superior às demais concorrentes locais, a capacidade técnica da emissora gaúcha é inferior à geradora. Os equipamentos de alta definição, assim como as ilhas de edição não-linear, são reservados a atrações semanais, como Galpão Crioulo, Patrola, Vida e Saúde e, principalmente, ao Núcleo de Programas Especiais, para produções mais elaboradas.

Inicialmente, as contribuições do Núcleo estão inseridas nas formas de viabilização de produção audiovisual predominantes no Rio Grande do Sul e em todo o país, como o patrocínio publicitário e o sistema de benefício público através das leis de incentivo fiscal e concursos promovidos por empresas estatais, o principal meio. Tal situação inviabiliza grande parte dos projetos e dificulta a sobrevivência de profissionais do meio, pois passam muito tempo captando recursos, em detrimento da efetiva produção.
4. Comercialização das produções em DVD e canal fechado, divulgando a produção local.

A RBS TV oferece cachês abaixo dos valores estabelecidos pelo Sindicato Interestadual dos Trabalhadores da Indústria Cinematográfica e Audiovisual (STIC), conforme tabela da convenção coletiva de trabalho para 2007/2008 para profissionais de longa, média e curtasmetragens.

Pelas normas do STIC, os trabalhadores devem ser pagos por semana de atividade, enquanto na emissora gaúcha os cachês são fechados por trabalho realizado, com exceção dos diaristas (diretor de fotografia, eletricistas, maquinistas, etc.). Mas não se identifica fiscalização. A comparação pode ser feita em relação à produção de curtas-metragens (filmes com duração máxima de 20 minutos) e a série Histórias Extraordinárias (programas em vídeo com o máximo de 15 minutos), conforme resumo da tabela 1.

Tabela 1. Comparação de valores: STIC X RBS TV

\begin{tabular}{|l|ll|l|}
\hline Funções & STIC & RBS TV (jan. 2007) & Tempo de envolvimento* \\
Assistente de direção & $\mathrm{R} \$ 8.526,00$ & $\mathrm{R} \$ 1.200,00$ & 8 semanas \\
Assistente de produção & $\mathrm{R} \$ 3.607,16$ & $\mathrm{R} \$ 400,00$ & 4 semanas \\
Diretor cinematográfico & $\mathrm{R} \$ 21.315,20$ & $\mathrm{R} \$ 3.500,00$ & 10 semanas \\
Diretor de fotografia & $\mathrm{R} \$ 7.378,30$ & $\mathrm{R} \$ 1.750,00$ & 5 diárias \\
Diretor de produção & $\mathrm{R} \$ 7.378,30$ & $\mathrm{R} \$ 1.800,00$ & 5 semanas \\
Eletricista-chefe & $\mathrm{R} \$ 5.328,75$ & $\mathrm{R} \$ 1.000,00$ & 5 diárias \\
\hline
\end{tabular}

* Período sujeito a variação, de acordo com as dificuldades/especificidade de cada produção.

Fonte: STIC. Piso salarial. Disponível em <http://www.stic.com.br/piso_salarial.htm>. Acesso em: 7 de julho de 2007.

Hoje, a produção do Núcleo de Programas Especiais classifica a RBS TV como única emissora regional com trabalho sistemático de produção audiovisual. Atualmente são estas as principais formas de incentivo à produção local:

1. Concurso público Histórias Curtas, que desde 2001 vem premiando projetos para roteiros;

2. Exibição de curtas-metragens gaúchos em destaque (Curtas Gaúchos), valorizando um mercado praticamente não rentável;

3. Terceirização da produção, com séries fixas (Minha História de Natal, Histórias Extraordinárias e Histórias Curtas) e séries eventuais (Sete Pecados, Amor de Mãe, entre outros), dando oportunidades para inúmeros profissionais, iniciantes ou não;
Antes da estreia oficial do Núcleo de Programas Especiais, foi veiculada a série de programas documentais 20 Gaúchos que marcaram o século XX. Em 2000, entraram no ar os primeiros programas produzidos com características próximas aos atuais, envolvendo cuidado estético, roteiros bem estruturados e melhor acabamento da imagem. No dia $1^{\circ}$ de janeiro foi exibido o musical Pra Sempre, seguido pelo sucesso da série Curtas Gaúchos - responsável por conquistar o espaço na grade dos sábados, às $12 \mathrm{~h} 20 \mathrm{~min}$, finalizando $\mathrm{o}$ ano com o programa de maior apelo popular até hoje, Minha História de Natal, e o especial Natal Luz.

Em 2001, a linha de produção encaminha-se para o que se entende hoje como Núcleo de Programas Especiais da RBS TV. Neste ano, a série Mundo Grande do Sul possibilitou a circulação de inúmeros realizadores nas 
dependências da emissora. Foram produzidos 14 programas com equipes de no mínimo seis pessoas.

Numa parceria com a Casa de Cinema de Porto Alegre veiculou-se em seguida a série Contos de Inverno, curtas de ficção em vídeo, com a proposta de conquistar o espectador com uma produção feita com atores, temas e sotaque gaúchos, em locações conhecidas pelo público. O grande destaque de 2001 foi para o prêmio Histórias Curtas, com seleção através da inscrição de roteiros e orçamentos, sendo a exibição garantida em janela televisiva, aos sábados, às $12 \mathrm{~h} 20 \mathrm{~min}^{1}$. Contudo, as oportunidades não se restringem ao prêmio, como resume Montanari:

O Núcleo fixou um mercado de uma produção televisiva gaúcha que foge do formato do telejornalismo até então produzido. Antes esse mercado já existia, mas era muito tímido e com produções muito esporádicas. Além de representar uma produção que se firmou como algo constante aqui no estado, veio abrir as portas para a produção do gênero ficção na televisão do Rio Grande do Sul, além de fomentar a produção de documentários. Com isso, contribuiu para o surgimento de novos nomes de profissionais da área audiovisual representando, também, fonte de emprego e renda, além de estimular a criação de novos projetos. Digamos que ele, o Núcleo, é uma boa ajuda para "aquecer" o mercado da produção audiovisual gaúcha (Montanari, 2007).

Até 2006 os formatos dos programas de teledramaturgia exibidos pela RBS TV equivaliam aos curtas-metragens: tramas de duração breve, com começo, meio e fim, dando espaço à diversificação autoral do diretor, sempre inserida na proposta central do Núcleo. No entanto, em novembro de 2006 foi ao ar A Ferro e Fogo, adaptação da obra de Josué Guimarães, série de ficção em três capítulos que representou o primeiro passo no investimento em produções de maior duração (90 minutos), aproximando as necessidades do trabalho às de um longametragem: equipes maiores, gastos superiores, tempo mais elevado de produção e, consequentemente, de edição.

Assim, em 2007 foram realizados dois grandes projetos, Pé na Porta e Loja da Esquina, ambos divididos em capítulos e com uma proposta seriada. Os profissionais atuantes no Núcleo de Programas Especiais da RBS TV são oriundos do cinema, vídeo e publicidade. Até 2001, não existia um mercado de produção de teledramaturgia no Estado, o que inviabilizava qualquer tipo de especialização na área.

Com o prêmio Histórias Curtas e o rápido aumento das produções da RBS TV, foi se criando o hábito de dirigir, produzir e atuar para televisão. Levantamento realizado junto às produções veiculadas pelo Núcleo no período de 1999 até 2006 verificou-se que estiveram envolvidos, no total, 5.850 profissionais técnicos nas equipes de produção, além de 1.098 atores.

\section{Estrutura e programas}

Com uma estrutura física e humana relativamente simples, a produção funciona de forma terceirizada. Os profissionais são contratados para a realização dos projetos, cuja coordenação de produção e direção geral são internas. As imagens são feitas por funcionários cinegrafistas, treinados para operar o equipamento oferecido pela casa. À medida que os programas ficaram mais elaborados, as equipes aumentaram. Em 2006, o especial noturno de três capítulos A Ferro e Fogo, com duração total de 90 minutos, contava com o trabalho de mais de 60 pessoas, número equivalente às equipes de filmes longa-metragem.

A equipe fixa se concentra em uma estrutura física simples, dividida em duas salas no prédio da RBS TV, em Porto Alegre, onde trabalham o diretor geral, a coordenadora de produção e seus assistentes e onde acontecem as produções.

As equipes enxutas e a verba curta são as dificuldades para o trabalho na produção de qualquer programa de ficção da RBS TV. No entanto, ter o nome da casa e a garantia de exibição para um público de 1 milhão de espectadores atrai apoiadores, além de dar credibilidade nas solicitações a órgãos públicos e privados. Produções independentes, por exemplo, não podem garantir aos apoiadores que o produto será veiculado, pois seu circuito comercial é restrito e depende da seleção em festivais e mostras. O risco que se corre de não haver audiência na RBS TV é pequeno, mas isto, de qualquer forma, não atinge o produtor contratado.

Tendo realizado o seu trabalho de produção não há por que se preocupar com as formas de distribuição do produto, estas estão garantidas. Além da exibição em canal aberto, o conteúdo é reprisado duas vezes no canal UHF da mesma rede, a TV Com. Além disso, diversos programas (Histórias Curtas, Teixeirinha, etc.) já foram comercializados para o Canal Brasil, muitos viraram DVD (A Ferro e Fogo, Cinco Vezes Erico, Quintana Anjo e Poeta, entre outros) e é possível assistir a boa parte da programação recente pelo portal de internet ClicRBS.

A divulgação da programação é feita principalmente através dos veículos da RBS. Matérias nos jornais e chamadas nas rádios da empresa, assim como vinhetas distribuídas pela grade semanal da RBS TV e da TV Com, são essenciais para atrair o público. O Núcleo tem ainda comunidade e perfil no portal de relacionamento Orkut, atualizado frequentemente com fotos e informações sobre os programas.

O público gaúcho é tido como conservador, por isso novos conceitos devem ser inseridos lentamente em seu cotidiano. É dessa forma que o Núcleo lida com a audiência: procura manter alguns padrões e eventualmente sugere novas formas. A linha clássica de documentários presentes na série 20 Gaúchos que marcaram o século XX está sendo aos poucos substituída. Um bom exemplo de mudança é o episódio Porto Alegre de Quintana, da série Quintana anjo e poeta, exibida em 2006, relatando o traba- 
lho do poeta gaúcho na capital rio-grandense.

Com o passar dos anos, a programação foi se fortalecendo e conquistando o respaldo publicitário, possibilitando o investimento em tecnologia. A câmera Beta SX (mesma utilizada pelo telejornalismo) foi substituída por uma mini-DV 24P e adquiriu-se uma câmera HDV (alta definição). Há uma preocupação do Núcleo em acompanhar as tendências do mercado audiovisual, inclusive em termos de edição de imagem. Em 2007, foi adquirido um steadycam, equipamento utilizado para estabilizar os movimentos de câmera. Além disso, máquinas ultrapassadas foram substituídas, por ilhas com o software Final Cut, utilizado por montadores do cinema e da publicidade, além de outros programas de finalização de imagem e áudio. pesquisa em todo o Estado, na busca de fatos e lendas curiosas. Após a seleção das melhores histórias, são contratados roteiristas e diretores para realizarem as adaptações. A coordenação do Núcleo, com o roteiro pronto, chama produtores e monta as equipes, de acordo com as necessidades do diretor.

HC é a série de curtas realizados através de um concurso de roteiros. Aos vencedores, o Núcleo paga uma quantia em dinheiro, oferece câmera, cinegrafista e finalização, acompanhando de fora o processo de produção. Em 2007 o prêmio foi de R\$ 35 mil, tendo sido contemplados oito roteiros de ficção, uma animação e um documentário. Após a exibição de todos os programas, um júri premia individualmente os envolvidos.

Tabela 2. Valor de diárias 2006 × 2007

\begin{tabular}{|c|c|c|}
\hline Função & Histórias Extraordinárias (2006) & Viajantes (2007) \\
Direção de fotografia & $\mathrm{R} \$ 350$ & $\mathrm{R} \$ 450$ \\
Eletricista & $\mathrm{R} \$ 200$ & $\mathrm{R} \$ 250$ \\
\hline
\end{tabular}

Fonte: autores

Quanto aos equipamentos de iluminação, a televisão disponibiliza um kit básico de luz, sendo necessário locar material extra para produções mais elaboradas. Para isto, a coordenação de produção do Núcleo realiza um sistema de rodízio, que contempla várias locadoras gaúchas. Em troca de logotipo nos créditos dos programas estas empresas ofertam enormes descontos, visando uma futura parceria com o Núcleo.

Foram ao todo 339 episódios exibidos, entre janeiro de 2000 e julho de 2007, na grade fixa de sábados, às 12h20min, e, na sazonal, aos domingos de noite, este para programas de até 30 minutos. Até a exibição do especial A Ferro e Fogo (2006), obra em três capítulos seriados, o material produzido sempre foi de caráter único, ou seja, o conteúdo da programação poderia ser assistido de forma independente. No entanto, a adaptação da obra de Josué Guimarães representou um marco na produção do Núcleo. A partir dela, duas outras séries, divididas em capítulos, foram produzidas: Pé na Porta e Loja da Esquina.

A grade de programação dos especiais é planejada com antecedência e a partir dela são pautados os programas a serem exibidos no ano seguinte. As séries fixas são Histórias Extraordinárias (HE), Histórias Curtas (HC) e Minha História de Natal (MHN). Com propósitos diferentes, cada uma apresenta suas peculiaridades de produção. HE é uma série na qual são dramatizados causos que alimentam a imaginação popular, mesclando depoimentos e ficção.

Seis meses antes da sua gravação é realizada uma
MHN é a série com menor orçamento do Núcleo, pautada num concurso de cartas, onde são escolhidas as 12 melhores histórias de Natal, obrigatoriamente de cada sucursal da rede. Uma equipe reduzida é contratada para viajar por todo o Rs e dar vida aos fatos relatados nas cartas. Quando exibidos, os telespectadores podem votar na história preferida, que será contemplada com um prêmio especial.

A grade de domingo é reservada a uma programação diferenciada. Cenas de simulação de sexo ou de drogas podem ser incluídas, havendo espaço para documentários. Ainda não há uma série fixa, pois a produção destinada a este espaço é relativamente recente. O horário disponível aos sábados obriga que os programas tenham duração máxima de 20 minutos, enquanto a grade sazonal aos domingos de noite permite meia hora de duração e uma classificação etária mais avançada. Segundo Perin (2007), a diferença entre as grades de sábado e domingo, além da duração, é a temática e as propostas estéticas. "Independente do horário, a exibiçãoéem TV aberta e o público gaúcho gosta de se ver retratado na tela".

\section{Resultados e mercado}

Desde 2000, vem se desenvolvendo uma produção sistemática de teledramaturgia na programação da RBS TV. Com programas de gêneros (aventura, drama, romance, suspense, etc.) e formatos variados (documentários, ficção ou mistos), a grade de sábados, 12h20min, está consolidada. Logo, o Núcleo de Programas Especiais trabalha de forma ininterrupta para que semanalmente um 
produto inédito vá ao ar. Enquanto um trabalho está sendo finalizado, outros estão nas fases de roteiro, produção e execução paralelamente, realizando uma espécie de círculo produtivo, no qual o processo tende a repetir-se infinitamente.

O sistema de produção de dramaturgia da RBS TV visa à fidelização máxima da audiência, buscando vender a capacidade de atenção deste público ao mercado publicitário. Com as séries A Ferro e Fogo, Pé na Porta e Loja da Esquina, surge a necessidade de uma forte divisão e especialização do trabalho criativo, com a contratação de profissionais da área, capacitados e experientes. Por conseguinte, implicam maior lucratividade para o Núcleo, já que atraem público, reduzem o tempo de realização das tarefas e diminuem os riscos de falhas. As diferenças entre valores de diárias na equipe de fotografia estão expostas na tabela a seguir.

\section{Tabela 3. Espaço comercial 30" na RBS TV - Especiais x Novela das 20h}

\begin{tabular}{|lll|}
\hline Programa & Especiais & Novela III \\
Dia & Sábado & Seg/Sab \\
Horário & 12h20min & 20h55min \\
RS-E (estado) & R \$ 8.458 & R \$23.301 \\
RS-2 (interior) & R 5.451 & R \$9.053 \\
RS-1 (Porto Alegre) & R 3.007 & R $\$ 14.248$ \\
\hline
\end{tabular}

* Lista de preços válida para out de 2007.

Fonte: RBS TV. Comercial. Porto Alegre: out de 2007.

A consolidação de um acervo de figurino e objetos cenográficos, além do arquivo de imagens pertencente à RBS, possibilita facilidades na realização, tanto em termos de pesquisa, quanto de reaproveitamento de materiais. Programas como a série Loja da Esquina tiveram seus custos reduzidos, já que muitas cenas foram compostas a partir do arquivo da TV e do jornal Zero Hora.

Ao mesmo tempo, o Núcleo não goza de autonomia plena na programação da grade. Programas históricos sobre a Revolução Farroupilha são anualmente exigidos pelos patrocinadores, mesmo que o tema já esteja esgotado. Em setembro de 2007, foi ao ar o programa Herança Farroupilha (ClicRBS, 2007), com roteiro criativo, comprovando que é possível driblar as exigências do marketing, de modo a satisfazer, simultaneamente, público e patrocinador.

O lucro previsto com a programação está ligado principalmente à audiência dos espaços pré-estabelecidos na grade (RBS TV e reprise na TV Com). Distribuição em DVD, comercialização para outras emissoras e premiações em festivais são encarados como um extra no faturamento do grupo, não chegando ao Núcleo porcentagem alguma desta arrecadação. Formas alternativas de distribuição dos produtos televisivos de ficção permitem uma maior circulação do trabalho, gerando reco- nhecimento aos autores.

Por enquanto, nenhuma emissora gaúcha possui estrutura para competir com a produção de teledramaturgia da RBS TV. Apesar de algumas tentativas da TVE-RS em produzir ficção televisiva, com a série Histórias do Sul e o projeto $D O C T V$, estas realizações não chegam a representar concorrência. Em curto prazo, a única possibilidade de alteração da supremacia da RBS TV em teledramaturgia no Estado é um eventual investimento da Rede Record.

Por outro lado, em 2007, a TV Com lançou a telenovela adolescente $^{2}$ Vida normal, uma continuação da série $P O A$ $R S$, anteriormente exibido pela TV Ulbra, canal universitário UHF, e pelo canal comunitário do cabo. Mas a TV Com é uma emissora da própria RBS, com abrangência na região metropolitana de Porto Alegre.

\section{Considerações finais}

Após sete anos de existência o Núcleo de Programas Especiais da RBS TV apresenta um sistema de produção nos moldes de Indústria Cultural. Baseado num trabalho circular e seriado, dia-a-dia a equipe responsável dedica-se à preparação dos programas, que devem preencher a grade fixa dos sábados.

Este espaço possibilitou que se estruturasse uma linha de produção de dramaturgia eletrônica na emissora inédita localmente. A padronização da sua produção ocorre especialmente nos sábados, em que programas de 15 minutos objetivam alcançar um público semelhante. Já a conquista da grade sazonal aos domingos à noite veio para acrescentar variedade temática e temporal no repertório.

A necessidade de preencher semanalmente a grade conduziu a um sistema de produção seriado, com o ímpeto de conquistar o maior número de espectadores, pelo mínimo custo possível. Para isso, conta com uma estrutura humana básica - habituada com as normas de funcionamento da casa " e física (ilhas de edição, equipamentos de captação, computadores, telefones e carros), além dos acervos disponíveis e suas outras mídias, que contribuem na divulgação dos produtos. Não existe estrutura de produção de teledramaturgia semelhante no RS e, dentre as afiliadas da Rede Globo, a RBS é a que mais produz localmente.

O foco é valorizar a cultura gaúcha, através da informação e do entretenimento, identificando-se públicoalvo, formatos e objetivos. Os programas inicialmente apresentavam temáticas semelhantes, o que foi modificado. Com exceção das séries fixas, a direção do Núcleo procura variar a programação, buscando unir sucessos de audiência e criatividade. A série Sete Pecados exemplifica o propósito: sete programas experimentais de depoimentos e dramatização. A experimentação destaca-se nas cores da arte e nos efeitos da fotografia.

Por questões de estrutura e custo, o Núcleo busca o suporte de produtoras do mercado gaúcho, com as quais negocia uma quantia de dinheiro em troca do produto 
encomendado. A produção é realizada extra-RBS TV, devendo os contratados seguirem as decisões do diretor geral interno. Esta parceria contribui para o desenvolvimento do mercado audiovisual local, movimentando o meio de trabalho.

O sistema de produção do Núcleo de Programas Especiais aproxima-se do trabalho de produtoras de vídeo e cinema. Os profissionais são os mesmos e estão cada vez mais ambientados com a dramaturgia para televisão. Diretores, roteiristas, atores e técnicos oriundos da publicidade, cinema ou vídeo contribuíram para este acontecimento. Sem concorrência para esta área, tal quadro pode se alterar se a Record resolver investir no setor.

Caso venha a montar um setor de produção audiovisual nos moldes dos Especiais, seguindo a tendência nacional da rede, que copia os passos da emissora líder, é possível que ocorra uma valorização do profissional e uma maior qualificação do conteúdo produzido, além do aprimoramento técnico consequente e necessário. Essa situação irá aproximar o mercado audiovisual local à realidade do sistema econômico televisivo nacional, inserindo o RS mais intensamente na Fase da Multiplicidade da Oferta afamecos

\section{NOTAS}

1 O concurso de vídeos com duração de um minuto, chamado de Minimetragem, lançado em 2007, também significou chance de destaque aos iniciantes. Os minicurtas vencedores foram exibidos antes de cadaprograma da série Histórias Curtas.

2 A RBS TV já havia produzido e exibido uma série adolescente, a inovadora Pé na Porta, que chegou a outras mídias, como a internet, com chats após os episódios e disponibilização de vídeos, fotos e áudios, e telefonia móvel. Para o celular, uma operadora disponibilizou a possibilidade de baixar ringtones com trechos da trilha sonora do programa.

\section{REFERÊNCIAS}

ALMEIDA FILHO, Hamilton. O ópio do povo: o sonho e a realidade. São Paulo: Símbolo, 1976.

BUSTAMANTE, Enrique. La televisión económica: financiación, estrategias y mercados. Madrid: Gedisa, 1999.

BRITTOS, Valério. Introdução. In: (Org.). Comunicação na fase da multiplicidade da oferta. Porto Alegre: Nova Prova, 2006. pp. 13-20.

; MIGUEL, João. Indústria cultural: conceito, especificidades e atualidade no capitalismo contemporâneo. In: BRITTOS, V.; CABRAL, A. (Orgs.). Economia política da comunicação: interfaces brasileiras. Rio de Janeiro: E-papers, 2008. pp. 37-56.
CLIC RBS. Programas Especiais. Disponível em: $<$ www.clicrbs.com.br>. Acesso em 10 de outubro de 2007.

KURTH, Estela. A contribuição das afiliadas na formação das redes nacionais de televisão no Brasi. Dissertação de Mestrado da Universidade Federal de Santa Catarina. Florianópolis.

LLOBET, Liliana. La proximidad como factor de valor noticioso y las identidades locales. Eptic On lineRevista Electrónica Internacional de Economía de las Tecnologías de la Información y de la Comunicación, Aracaju: v. 4, nº. 2, 2000. Disponível em: <http:/ /www.eptic.he.com.br/EPTIC\%20IV-2.pdf>. Acesso em 10 de setembro de 2007.

LOPES DA SILVA, Manoel. Prefácio. In: BRITTOS, V. (Org.). Comunicação na fase da multiplicidade da oferta. Porto Alegre: Nova Prova, pp. 7-11, 2006.

MONTANARI, Hique. Entrevista concedida pelo diretore roteirista free lancer do Núcleo de Programas Especiais da RBS TV, Porto Alegre. Porto Alegre, em 12 de outubro de 2007.

MOSCO, Vicent. Economia política da comunicação: uma perspectiva laboral. Comunicação e sociedade 1-Cadernos do Noroeste, Braga, v. 12, nº. 1 e 2. pp. 97-120, 1999.

PERIN, Gilberto. Entrevista concedida pelo diretor geral do Núcleo de Programas Especiais da RBS TV, Porto Alegre. Porto Alegre: 12 de outubro de 2007.

RBS TV. Comercial. Porto Alegre: outubro de 2007.

SIMÕES, Roberto. Entrevista concedida pelo gerente de programação da RBS TV. Porto Alegre: em 21 de maio de 2007.

STIC. Piso salarial. Disponível em: <http:// www.stic.com.br/piso_salarial.htm>. Acesso em 7 de julho de 2007. 